\title{
Programmed delivery of verapamil hydrochloride from tablet in a capsule device
}

\author{
Mukesh Lal Sah ${ }^{1, *}$, Vijay Juyal ${ }^{2}$ \\ Devsthali Vidyapeeth College of Pharmacy, Rudrapur, Uttarakhand, India, ${ }^{2}$ Department of Pharmaceutical Sciences, Bhimtal \\ Campus Kumaun University, Nainital, Uttarakhand, India
}

\begin{abstract}
The aim of the present work was to develop a programmed drug delivery system which would be able to release the drug after $6 \mathrm{~h}$ of lag time by use of hydrophilic polymers. The capsule body was made impermeable by use of formaldehyde vapor treatment, while the cap was untreated. The capsule was filled with two layered tablets (tablet-in-capsule), followed by a sodium bicarbonate:citric acid mixture (SBCM) and lactose as bulking agent. Sodium alginate, chitosan, HPMC K15 and chitosan:sodium alginate complex (CSAC) were used as the rate modulating layer. Through combined use of HPMC $\mathrm{K} 15$ and adjusting the ratio of CSAC, the desired lag time of $6 \mathrm{~h}$ was obtained. The effect of the bulking agents on the lag time were also studied and it was found that the lag time was decreased with higher amounts of lactose, and delayed dissolution and decreased lag time was observed at higher amount of effervescent mixture.
\end{abstract}

Uniterms: Circadian rhythm. Chitosan/sodium alginate complex. HPMC K15. Lactose. Effervescent mixture.

O objetivo do presente trabalho foi desenvolver sistema de liberação programada de cloridrato de verapamil capaz de liberação imediata do fármaco após $6 \mathrm{~h}$ de intervalo de tempo usando polímeros hidrofílicos. O corpo da cápsula foi impermeabilizado por tratamento de vapor de formaldeído, enquanto a tampa não foi submetida ao tratamento. Dois comprimidos foram inseridos na cápsula (comprimidos em cápsula) seguido de mistura de bicarbonato de sódio: ácido cítrico e lactose, utilizados como excipientes. O alginato de sódio, a quitosana, o HPMC K15 e o complexo quitosana:alginato de sódio foram utilizados para modular a razão de liberação do fármaco. A combinação entre o HPMC K15 e o ajuste da proporção do complexo quitosana:alginato de sódio permitiu a liberação do fármaco após $6 \mathrm{~h}$. O efeito dos excipientes na liberação do fármaco foi também avaliado. Verificou-se que o tempo de latência foi reduzido na presença de maior quantidade de lactose, enquanto o menor tempo foi observado empregando maior concentração da mistura efervescente.

Unitermos: Ritmo circadiano. Quitosana/complexo de alginato de sódio. HPMC-K15. Lactose. Mistura efervescente.

\section{INTRODUCTION}

The delivery of the desired dose of a drug at a predetermined time has always been the prime objective of drug delivery systems. Novel drug delivery systems have the potential to provide antihypertensive medication at the time when the need is greatest (Elliott, Prisant, 1997; Prisant et al., 1992). The disease symptoms, such as hypertension,

*Correspondence: Mukesh Lal Sah. Devsthali Vidyapeeth College of Pharmacy, Rudrapur, Uttarakhand, India. E-mail: mukeshlalsah@gmail.com ischemic heart disease, asthma and rheumatoid arthritis, exhibit circadian rhythms (Lemmer, 1991; Traynor et al., 1992; Vyas et al., 1997). Cardiovascular diseases, which account for the greatest morbidity and mortality, are greatly affected by body rhythms (Muller, 1999). Moreover, treatment outcomes may be affected by body rhythms. Failure to recognize these points may account for chronopathological events, including anterior ischemic optic neuropathy (Hayreh, 1999) and cerebrovascular accidents among persons with hypertension whose blood pressure falls markedly during the night ("extreme dippers") (Kario et al., 1996). It 
is recognized that myocardial infarctions, sudden cardiac death, transient ischemic attacks and cerebrovascular accidents occur at a higher frequency in the early hours of the morning. Most cardiovascular medicines are designed to achieve a constant, or near-constant, effect throughout the 24-hour dosing interval. In many cases, however, the requirement for medication is not the same at nighttime as it is during the day (Anwar, White, 1998). Many drugs have been studied with respect to their pharmacokinetics and chronopharmacology, including analgesics, anticancer drugs, antibiotics, psychoactive drugs, local anesthetics, antiasthmatics, anticonvulsants and beta-blockers (Ritschel, Forsuz, 1994).

In general, the release rate of a drug is controlled by using a polymer with opposite solubility to the drug, or by combining polymers of different solubilities, as the drug will diffuse out easily from the dosage form if the fabricated by polymer, or polymers, have the same solubility as the drug. This concept was used to deliver verapamil (Verelan PM) by using water soluble and insoluble polymers. The chronotherapeutic oral drug absorption system (CODAS) verapamil PM, (Verelan PM, Schwarz Pharma, Inc., Mequon, WI) was designed to provide a drug-release profile that complements the circadian pattern of blood pressure (Prisant, 2001). This technology incorporated an initial 4-5 h delay, followed by the extended release of verapamil.

One should not assume that a drug dosed in the morning will have the same antihypertensive effect as a drug dosed in the evening (Lemmer, 1996). Oral pulsed or delayed delivery systems are designed to elicit programmable lag phases preceding a prompt and quantitative, and either repeated or prolonged release of the drug (Maroni, 2010). Therefore, the present study was aimed to develop a drug delivery system, using hydrophilic polymers only, which would be able to release the drug immediately after the desired lag time of $6 \mathrm{~h}$. Verapamil was chosen as a representative drug, which is a potent calcium channel blocker and has been used for the treatment of essential hypertension and time related occurrence of disease symptoms (Lemmer, 1991).

\section{MATERIAL AND METHODS}

\section{Material}

Verapamil hydrochloride and HPMC K-15 were received as gift samples from Alembic Ltd. Vadodra, Gujarat, India. Empty capsule shells were received as gift samples from Erawat Pharma, Pithampur, Madhya Pradesh, India. Chitosan with $85 \%$ deacetylation was purchased from Marine chemicals, Kochi India. Sodium alginate was purchased from Loba chemie, Pvt. Ltd, Mumbai, India. All other reagents were of analytical grade and used as purchased.

\section{Preparation of impermeable capsules body}

For controlling the release of the drug from a novel tablet in capsule device, the body of the capsule was made impermeable, while the cap of the capsule remained soluble, so that dissolution fluid may enter from the soluble part of capsule. The body and the cap of the gelatin capsule (size 0 ) were separated. The body of the capsule was exposed to formaldehyde vapor for $6 \mathrm{~h}$ at room temperature and dried at $50{ }^{\circ} \mathrm{C}$ for $48 \mathrm{~h}$ in a hot air oven (Sropathy et al., 1999). The treated capsule body and the untreated soluble cap were stored in desiccators until used. Prior to use, the treated capsule body was studied for disintegration test and the treated capsule body did not show any signs of disintegration and was therefore used for the further study.

\section{Preparation of two layered tablets}

An accurately weighed amount of the powders, containing the immediate release layer and the rate modulating layers, were sifted through 80 mesh size, and then tablets were compressed in a $7 \mathrm{~mm}$ single punch machine by hand filling. The immediate release layer was composed of verapamil: lactose: cross povidone: magnesium stearate (20:65:10:5), while the rate modulating membrane was composed of polymers only.

\section{Studies of the rate modulating layer}

To select the material for the modulating layer, HPMC K15, chitosan and sodium alginate were chosen as candidates for the study, which are commonly used for controlled or sustained release $(n=6)$.

\section{Studies of weight of rate modulating layer on the release of drug}

HPMC K15, chitosan and sodium alginate alone, and chitosan and sodium alginate in different proportions at different weights $(100,150,200 \mathrm{mg})$ were compressed. To obtain mechanically stable tablets, the rigidities of the tablets were kept in the range of $8-10 \mathrm{~kg} / \mathrm{mm}^{2}$, as no significant effect of hardness was observed on the release of drug by Bin Li and co workers (Li et al., 2008). HPMC K15 has been studied for lag time by Mukesh C. Gohel (Gohel, Manhapra, 2002), which was further studied at the same weights to obtain the desired lag time $(n=6)$. 


\section{Studies of the amount of bulking agent on the release of drug}

To study the amount of bulking agent on the release of drug, lactose and sodium bicarbonate:citric acid (1:1) were used as bulking agents. 150, 175 and $200 \mathrm{mg}$ of lactose and 20,30 and $40 \mathrm{mg}$ of the effervescent mixtures were selected to study the effect of the amount of bulking agent on the release of drug $(n=6)$.

\section{Fabrication of the capsule device for two pulse drug release}

Two layered tablets containing the immediate release and the rate modulating layer, followed by the effervescent layer and lactose as filler were snuggly fitted in the impermeable capsule body (Fig. 1), and then the soluble cap was placed on the body. The first two layered tablet (A) was placed in the capsule body in such a way that the immediate release layer was facing the outer side, while the rate modulating layer faced inside. The layers (rate modulating and immediate release layer) of the second two layered tablet (B) were position facing the opposite way to first two layered tablet.

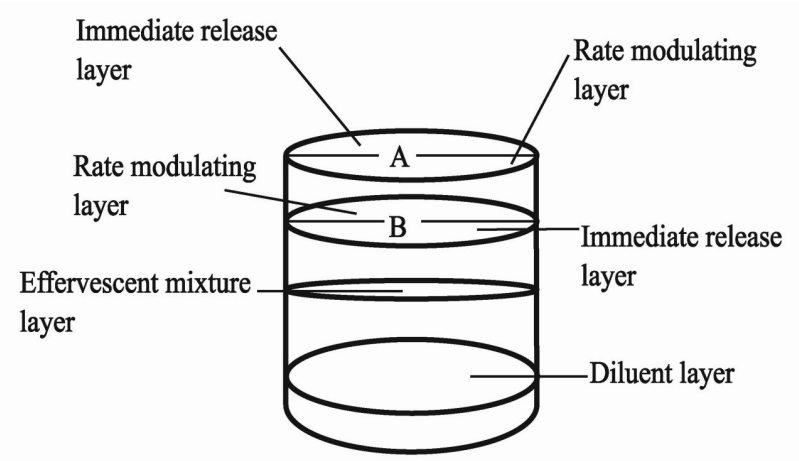

FIGURE 1 - Schematic presentation of the bi-layered tablets in the impermeable capsule body.

\section{In vitro drug release studies of the capsules}

A total of $900 \mathrm{~mL}$ of the dissolution medium ( $\mathrm{pH}$ 1.2) was used to fill the USPXXIII dissolution apparatus. The capsule $(n=6)$ was placed in a basket and the speed was adjusted to $100 \mathrm{rpm}$. The temperature of the dissolution medium was maintained at $37 \pm 0.5^{\circ} \mathrm{C}$. After $2 \mathrm{~h}$ stirring was stopped, the basket was washed with distilled water and the dissolution medium was replaced by phosphate buffer ( $\mathrm{pH}$ 6.8), which had previously been maintained at simulated body temperature. Aliquots $(10 \mathrm{~mL})$ were withdrawn at 15 min time intervals and the same volume replaced by fresh dissolution medium.

\section{RESULTS AND DISCUSSION}

The aim of the study was to develop a $\mathrm{pH}$ independent dosage form with a lag time of $6 \mathrm{~h}$ and fast release thereafter. The total weight of the layered tablet was kept at $200 \mathrm{mg}$ for the study.

\section{Effect of individual polymer on lag time}

Results in Figure 2 show that only HPMC K15 was able to provide a lag time of $6 \mathrm{~h}$. Only $7.5 \%$ of the drug was released after $6 \mathrm{~h}$, which satisfies the lag time criteria, but slow release was obtained thereafter, with only $20 \%$ of the drug being released after $8 \mathrm{~h}$, and complete release being seen after $10 \mathrm{~h}$. Lactose was added to the HPMC to reduce the swelling of HPMC gel at 10\%, 20\%, 30\%, 40\% and $50 \% \mathrm{w} / \mathrm{w}$, but lag time was not controlled.

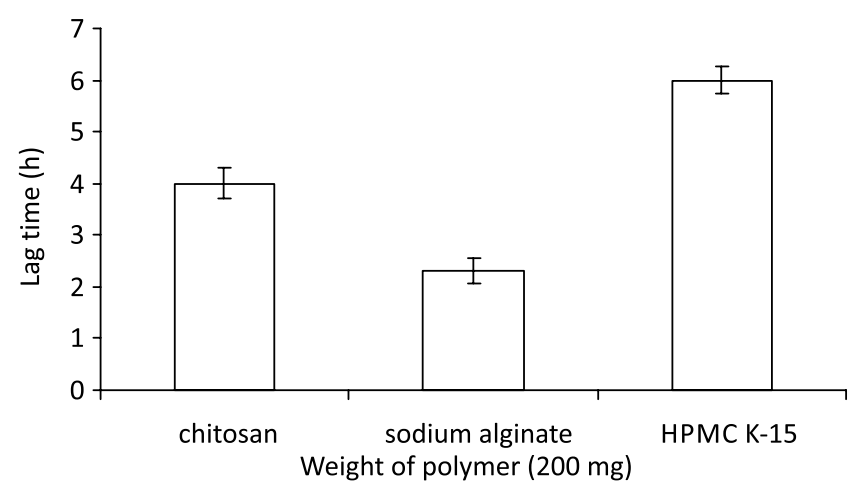

FIGURE 2 - Lag time of sodium alginate, chitosan and HPMC $\mathrm{K} 15$ at $200 \mathrm{mg}$ weight.

From Figure 2, it was also seen that chitosan and sodium alginate were not able to produce the desired lag time at maximum weight, and that lag time was dependent on the $\mathrm{pH}$ of the medium. Sodium alginate rapidly forms a viscous gel on contact with aqueous media. Because of its high dissolution characteristics, the drug rapidly diffuses through the gel and released all of its active ingredient in $3 \mathrm{~h}$, at the highest weight of polymer. Chitosan dissolves to some extent in inorganic mineral acids, hence providing the higher lag time of $4 \mathrm{~h}$ and the drug was released by initial low dissolution and then erosion of chitosan.

\section{Effect of CSAS}

A combination of chitosan with sodium alginate for sustaining the release of theophylline has also been studied, and release was found to be independent of the $\mathrm{pH}$ of the dissolution medium (Yamota et al.,1994). From the results, shown below (Figure 3), it was found that a lag time 
of $3 \mathrm{~h}$ was obtained from CSAS at a 50:50 ratio at $200 \mathrm{mg}$ weight. When the ratio of chitosan was increased then lag time was also increased, but significant increase $(p<0.05)$ was not observed. The complex produced by combining the chitosan and sodium alginate had no significant effect over chitosan and sodium alginate alone. Similar results were also obtained by Jittima and co-workers (Chatchawalsaisin et al., 2004).

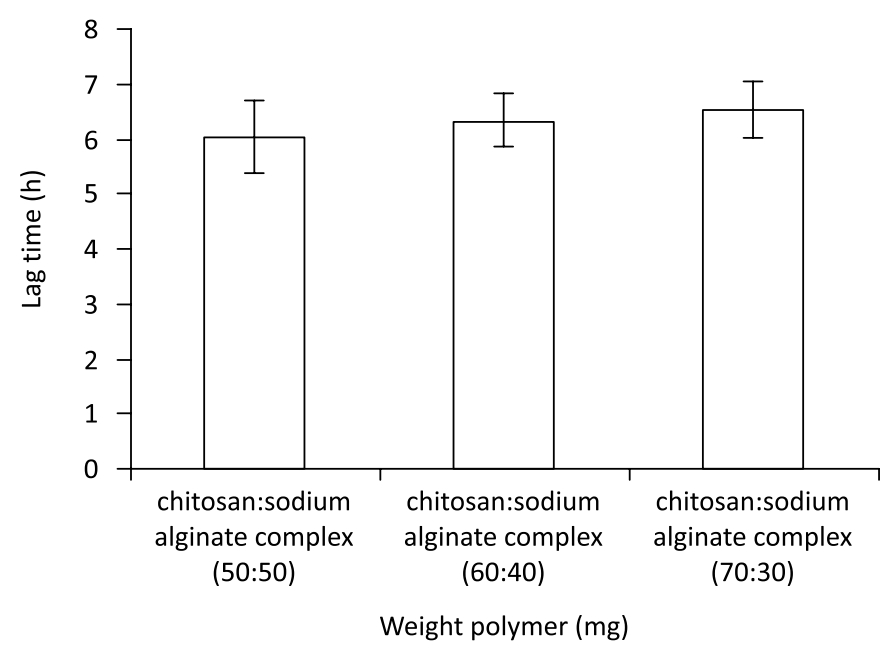

FIGURE 3 - Lag time of chitosan:sodium alginate polymer complex, in different ratio, at $200 \mathrm{mg}$ weight.

\section{Effect of HPMC K 15 and CSAS}

HPMC K-15 and CSAS, when used alternately as the rate modulating layer, gave the desired lag time of $6 \mathrm{~h}$, with only $8 \%$ of the drug being released from the formulation, which satisfies the lag time criteria. Lag time was found to be independent of $\mathrm{pH}$ and the drug was released mainly by diffusion, although through a dissolution/erosion mechanism.

\section{Effect of the SBCM on lag time/dissolution}

SBCM was added to hasten the release of drug after the desired lag time. No effect was observed at low amounts of SBCM (Figure 4), but at higher amounts the lag time was found to be reduced due to the pressure generated in the system by $\mathrm{CO}_{2}$ after dissolution of SBCM causing pressure on the gel matrix. Verapamil is a basic drug which is why the dissolution of the drug was also reduced as SBCM was increased.

\section{Effect of lactose on lag time}

Lactose was added as a bulking agent separately

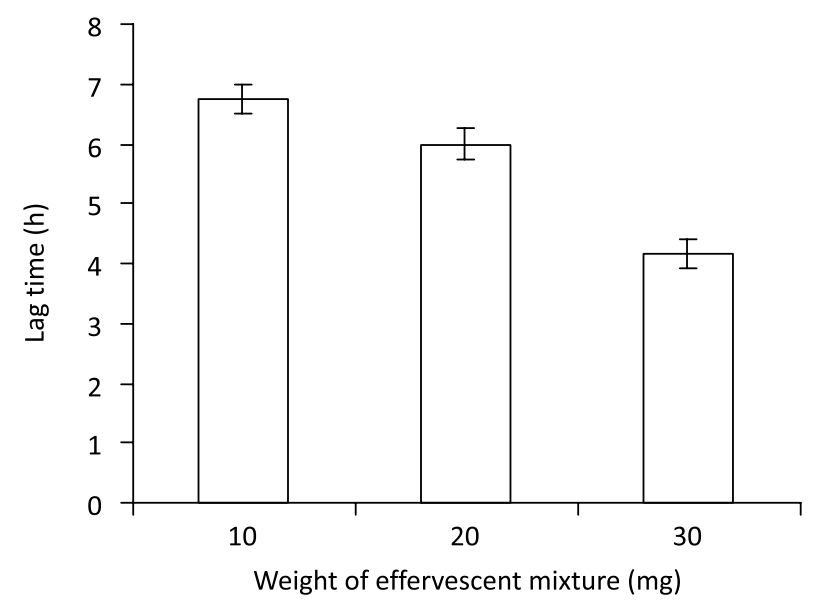

FIGURE 4 - Effect of the amount of effervescent mixture on the lag time of the rate modulating layer containing HPMC K15 and $\operatorname{CSAC}(50: 50)$ at different weights.

to ensure the proper position of the tablet in the capsule device, but a significant effect on the lag time of drug due to the amount of lactose was observed (Figure 5). The increasing hydrodynamic pressure in the system, due to dissolution of lactose, shortened the lag time.

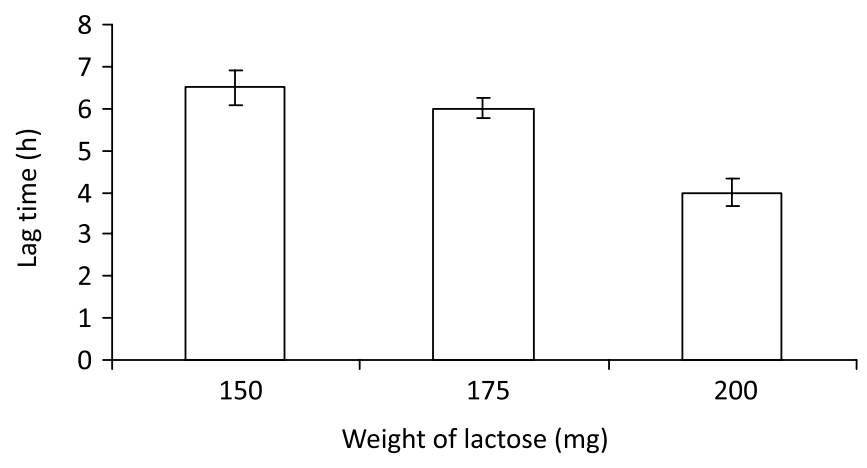

FIGURE 5 - Effect of the amount of lactose on the lag time of the rate modulating layer containing HPMC K15 and CSAC (50:50) at different weights.

\section{Investigation of two pulse release}

From the above results, two pulse release was successfully achieved (Figure 6) by using a bi-layered tablet containing $100 \mathrm{mg}$ of immediate release layer and $100 \mathrm{mg}$ of HPMC K 15 as a rate modulating layer, followed by $100 \mathrm{mg}$ of CSAC (50:50) as a rate modulating layer, $100 \mathrm{mg}$ of immediate release layer, and $20 \mathrm{mg}$ SBCM and $175 \mathrm{mg}$ of lactose. After $6 \mathrm{~h}$ of lag time, $85 \%$ release of drug was obtained within $15 \mathrm{~min}$. Complete release was obtained within $30 \mathrm{~min}$ and the release was reproducible. 


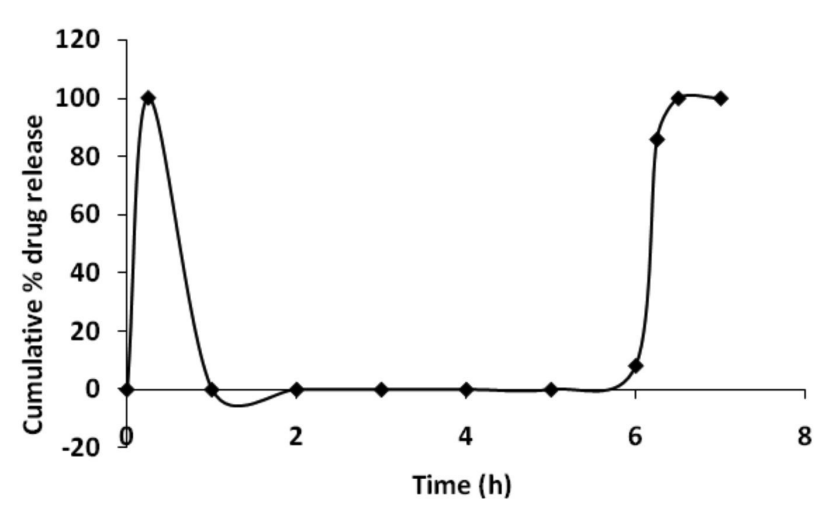

FIGURE 6 - In vitro release profile of two pulse release system, containing HPMC K15 (100 mg) and CSAC 50:50(100 mg) as rate modulating layers, $\mathrm{CBCM}(20 \mathrm{mg})$ and lactose $(175 \mathrm{mg})$.

\section{CONCLUSIONS}

Pulsed release of a drug with variable lag time has been studied by various scientists. Lag time can control by using a polymer of opposite solubility to the drug, or by combining hydrophilic and hydrophobic polymers. A higher lag time for a water soluble drug using a hydrophilic polymer is always difficult, as diffusion of the drug from the polymer is not controlled easily. The present system is capable of delivering the drug after $6 \mathrm{~h}$ of desired lag time. It is known that in most people with high blood pressure, there is a definite rise in blood pressure upon awakening (also termed the "A.M." surge), and that blood pressure then goes down starting in mid-afternoon, hence the proposed system could be used successfully, as a once daily does taken at night time, i.e. 10 p.m., which would enable delivery of the drug in the early morning i.e. 4 a.m.

\section{AUTHORS' STATEMENTS}

The authors declare no conflict of interest.

\section{ACKNOWLEDGEMENTS}

The authors wish to acknowledge Dr. Neelesh Chachda and Mr. Ashutosh JamLoki for providing the gift samples of gelatin capsule shell and verapamil hydrochloride.

\section{REFERENCES}

ANWAR, Y. A.; WHITE, W.B. Chronotherapeutics for cardiovascular disease. Drugs, v.55, p.631-643, 1998.
CHATCHAWALSAISIN, J.; PODCZECK, F.; NEWTON, M.J. The influence of chitosan and sodium alginate and formulation variables on the formation and drug release from pellets prepared by extrusion/spheronisation. Int. J. Pharm., v.275, p.41-60, 2004.

ELLIOTT, W.J.; PRISANT, L.M. Drug delivery systems for antihypertensive agents. Blood. Press. Monit., v.2, p.5360, 1997.

GOHEL, M.C.; MANHAPRA, S.G. Modulation of active pharmaceutical material release from a novel 'tablet in capsule system' containing an effervescent blend. J. Control Rel., v.79, p.157-164, 2002.

HAYREH, S.S. Role of nocturnal arterial hypotension in the development of ocular manifestations of systemic arterial hypertension. Curr. Opin. Ophthalmol., v.10, p.474-482, 1999.

KARIO, K.; MATSUO, T.; KOBAYASHI, H.; IMIYA, M.; MATSUO, M.; SHIMADA, K., Nocturnal fall of blood pressure and silent cerebrovascular damage in elderly hypertensive patients. Advanced silent cerebrovascular damage in extreme dippers. Hypertension, v.27, p.130-135, 1996.

LEMMER, B. Differential effects of antihypertensive drugs on circadian rhythm in blood pressure from the chronobiological point of view. Blood Press. Monit., v.1, p.161-169, 1996.

LEMMER, B. Circadian rhythms and drug delivery. J. Control. Rel., v.16, p.63-74, 1991.

LI, B.; ZHU, J.B.; ZHENG C.L.; GONG. W. A novel system for three pulse release based on "tablet in capsule" device. Int. J. Pharm., v.352, p.159-164, 2008.

MARONI A.; ZEMA L.; CURTO M.D.D.; LORETI, G.; GAZZANIGA A. Oral pulsatile delivery: Rationale and chronopharmaceutical formulations. Int. J. Pharm., v.398, p.1-8, 2010 .

MULLER, J.E., Circadian variation in cardiovascular events. Am. J. Hypertens., v.12, p.35-42, 1999.

PRISANT, L.M.; BOTTINI, B.; DIPIRO, J.T.; CARR, A.A. Novel drug-delivery systems for hypertension. Am. J. Med., v.93, p.45-55, 1992. 
PRISANT, L.M. Verapamil revisted: a transition in novel drug delivery systems and outcomes. Heart Dis., v.3, p.55-62, 2001.

RITSCHEL, W.A.; FORSUZ, H. Chronopharmacological: a review of drugs studies. Methods Find Exp. Clin. Pharmacol., v.16, p.57-75, 1994.

SROPATHY, M.; SRINATH M.S.; PARANJOTHY, K.L.K. Formulation of formaldehyde treated capsules containing diltiazem hydrochloride-polymer mixture and its in vitro release studies. Eastern Pharmacist, v.42, p.97-98, 1999.
TRAYNOR, K.; NEWTON, D.W.; HRUSHESKY W.J.M.; REITER R.J. A Pharmacist's primer on chronotherapeutics. Am. Pharm., NS32, p.261-267, 1992.

VYAS, S.P.; SOOD, A.; VENUGOPALAN, P.; MYSORE, N. Circadian rhythm and drug delivery design. Pharmazie, v.52, p.815-820, 1997.

YAMOTA, C.; MIYAZAKI, T.; OKADA, S. Sustained-release effect of direct compressed tablet based on chitosan and $\mathrm{Na}$ alginate. Yakugaku Zasshi, v.214, p.257-263, 1994.

Received for publication on $29^{\text {th }}$ June 2011 Accepted for publication on $2^{\text {nd }}$ March 2012 